\title{
Research on the Theory and Context of E-ELM Model from the Perspective of Entertainment Education*
}

\author{
Cheng Li \\ School of Art and Communication \\ Beijing Normal University, Zhuhai \\ Zhuhai, China \\ Department of Education and Learning Technology \\ National Tsing Hua University \\ Hsinchu, Taiwan
}

\begin{abstract}
The idea of entertainment education was proposed long ago. Based on this idea, the Extended-Elaboration Likelihood Model (E-ELM model) for entertainment education on narrative processing is formed. Based on this, the thesis elaborates the theoretical foundation of entertainment education laid down by social cognitive theory and triadic reciprocal determinism, discusses that the narration theory and transportation theory form the mechanism of entertainment education, explores the ELM model produced under the leadership of the persuasion theory, and finally revises it to form the E-ELM model.
\end{abstract}

Keywords-entertainment education; E-ELM model; narrative theory; social cognitive theory

\section{INTRODUCTION}

People around the world spend a lot of time everyday in participating in narratives. People read novels, watch TV series, or listen to news reports. These actions can change people's perception of the world - even if the characters or events in the narrative are fictional, they can achieve the effect of persuasion. Persuasion through narrative has something in common with other persuasion ways, but the mechanism of narrative persuasion is distinctly different from that of other persuasion ways. From the perspective of entertainment education, it is the fictional text that participates in narrative (such as television series). The audience is persuaded by the fictional narratives through their transport experience, which makes the beliefs of the audience more susceptible to the information in the narrative (Gerrig, 1993; Green And Brock, 2002). People read or listen to argument texts to obtain messages. People often need to understand these texts by positively elaborating them, and usually they cannot fully express the texts. At the same time, the narrative does not need

*This article is the research result of Beijing Normal University, Zhuhai 2018 Guangdong Province Education Science "the 13th Five-Year Plan Outline" Special Research Project on Moral Education "Research on the Impact of Internet Hot Topics on College Students' Ideas" (No. 2018JKDY04 and Beijing Normal University, Zhuhai 2018 Scientific Research Capacity Improvement Plan Project (No. 201850014). to demonstrate the authenticity and effectiveness of the information it provides, and novels, movies, and television shows don't need to prove their authenticity and validity. Narrative texts are often easy to understand and recipients can enjoy the pleasure of reading narrative texts. In view of this, Slater and Rouner (2002) developed a new model of narrative convincing.

\section{E-ELM MODEL}

This Extended-Elaboration Likelihood Model (E-ELM) is used to explain how persuasive content in entertainment education is handled, and it may lead to attitudes and behavior's being consistent with the message. In this model, narrative plays a key role in persuasion. It is believed in the model that the four factors of entertainment education message that use the way of narrative affect the transportation level of the audience: (1) the story line appeal (Is this the story the audience wants to see?); 2) The quality of production (how are the qualities of writing, editing, and shooting?); (3) The unobtrusiveness of persuasive subtext (can the audience realize that this message is trying to convince them?); (4) Role homosexuality (how similar is the role to the audience?)

According to E-ELM, transportation has an impact on content, interpersonal communication/discussion after receiving messages, and role identity. Role identity is also influenced by the degree of similarity between the audience himself and the character in the story. In this theory, transportation does not directly affect the attitudes or behavior effect of information, but it affects the audience's reactions, recognition, and discussion. Another major contribution of EELM is that it shows the major reason why E-ELM can achieve good narrative effect is that it can restrain viewers from resisting persuasion. Slater and Rouner (2002) concluded from the transport theory that audiences being transported were unlikely to rebut the information received (Green \& Brock, 2000) because when they were transported, the audiences were immersed in the story and could hardly extricate themselves to refute the message sent by the narrative. This article comprehensively combs the formation of the E- 
ELM from the aspects of social cognitive theory, triadic reciprocal determinism, entertainment education, narrative theory, transportation theory, persuasive theory and ELM, in order to deepen the understanding of the model.

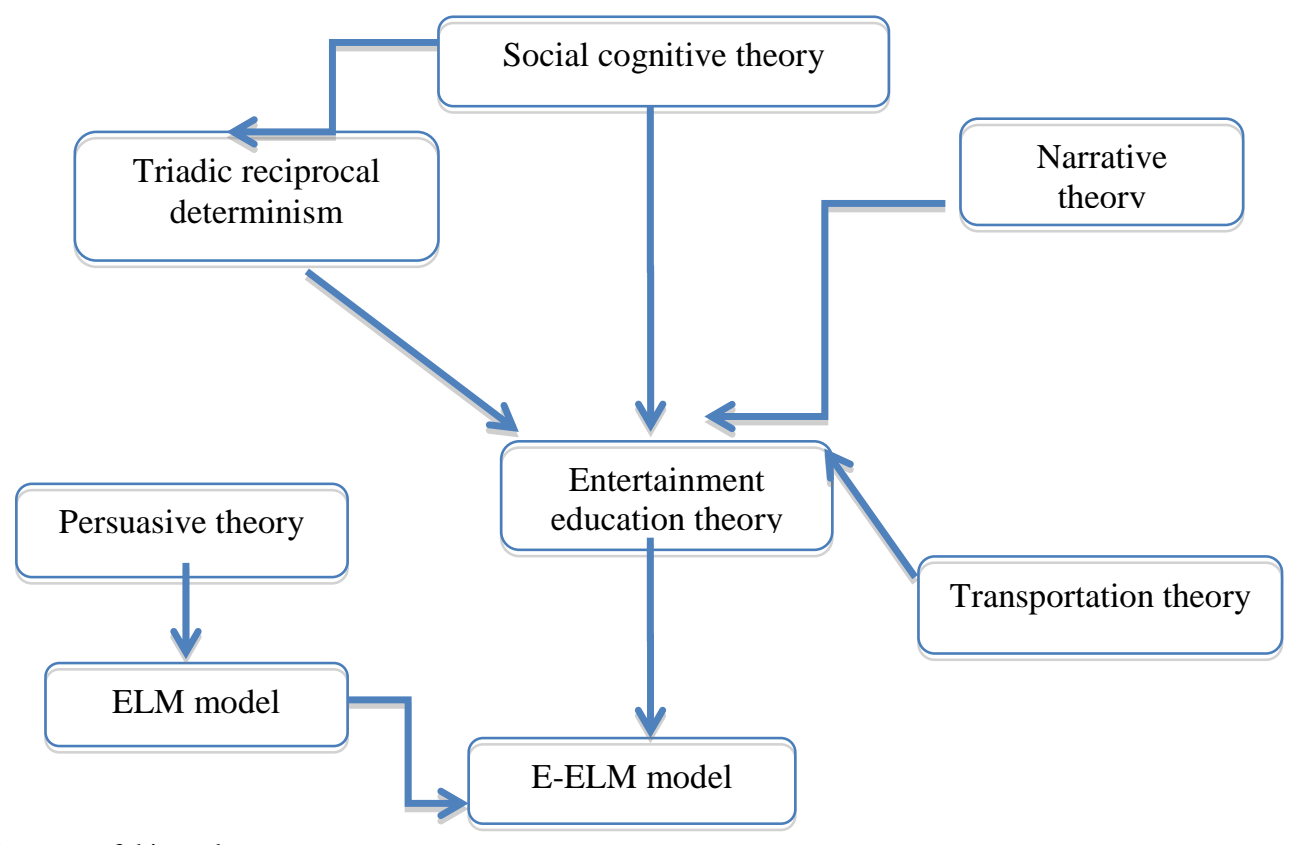

Fig. 1. The theoretical context of this study.

\section{SOCIAL COGNITIVE THEORY AND TRIADIC RECIPROCAL DETERMINISM LAID THE THEORETICAL FOUNDATION FOR ENTERTAINMENT EDUCATION}

The most commonly used theory in entertainment education is the social cognitive theory (SCT) proposed by Bandura in 1986. This theory holds that in addition to direct experiential learning, people can also learn indirectly by observing models (Bandura, 2002). In other words, models on TV can pass "knowledge, values, cognitive skills, and new behaviors" to the audience (Bandura, 2004, p. 78). A core premise of social cognitive theory (Bandura, 2004) is that individuals are more likely to imitate behaviors which they have seen than to imitate an act that is encouraged but not proven. The theory defines various modeling functions, including the acquisition of new behaviors, increasing or decreasing the frequency of previously acquired behaviors, and suppressing or repressing previously learned behaviors (Bandura, 2002). The core idea of social cognitive theory is that individual behavior is not only a product of the environment, but also influenced by individual cognitive factors. Cognitive factors, as mediators of stimulation and response, determine the behavior and state of individuals when they face environmental stimuli (Bandura, 1986).

Bandura (1971) believes that people will observe and imitate others' attitudes and behaviors under certain conditions. First of all, people must observe and remember the behavior they want to imitate. Second, people must have the ability and motivation to practice what they have learned. The Triadic Reciprocal Determinism based on this ideology reveals the individual's psychological behavior and the causal laws of the behavior. It is one of the core ideas of Bandura's social cognitive theory.

Triadic Reciprocal Determinism is the core of social cognitive theory and is also one of the theoretical foundations of entertainment education. Bandura (1986) pointed out that most of human thoughts originated from the development and deepening of their cognition. When cognitive processes and social work are in a state of harmony, a learning process takes place, in which three independent forces that influence and have interaction on each other occur, they are named: individual factors (individual cognitive factors), environmental factors, and individual behaviors. Bandura (1986) named it "Triadic Reciprocal Determinism".

Morgan, Movius and Cody (2009) pointed out that the application of social cognitive theory to entertainment education research is very useful for understanding the audience's ideas and intentions and exploring the formation of audiences' attitudes and behaviors. The Triadic Reciprocal Determinism is used in studying individual's learning behavior and is one of the core contents of social cognitive theory. This theory reveals the individual's psychological activity process and the causality of the psychological activity. Therefore, Bandura's Triadic Reciprocal Determinism provides a theoretical perspective for entertainment education, that is, we can conduct deep exploration on the mechanism in which entertainment media creates a mimicry environment to trigger interactions between individual behaviors, focusing on the three elements of individual, environment, and behavior. 


\section{NARRATIVE THEORY AND TRANSPORTATION THEORY} FORM THE MECHANISM OF ENTERTAINMENT EDUCATION

The idea of entertainment education is originated from Horace's "Edutainment" view and has existed for thousands of years. Today, there are more and more media with entertainment education function. The carriers of entertainment education have not been limited to literary and artistic works. Modern forms include radio, television, movies, museum exhibits, and various kinds of games. These entertainment media can both attract the attention of the audience and be artificially added to some educational content so that the audience can receive positive educational information while they are having fun. This can achieve the goal of "edutainment" and form the modern entertainment education theory.

Entertainment-education, abbreviated as E-E, means that use entertainment media which has both "entertainment" and "education" functions to increase audience's awareness of educational issues, create favorable attitudes, and change public behavior (Singhal \& Rogers, 1999). Singhal \& Rogers (2002) further intensified human intervention in entertainment education, arguing that this was "a strategy that intentionally places educational content in entertainment messages in order to transmit information that could cause social and behavioral changes", defining entertainment as the performance of personal interests or activities that can make the audience enjoyable. Slater (2002) believes that the purpose of entertainment education is to promote the transformation of social beliefs, attitudes and behaviors, and even to teach skills to the audience. Zillmann (2000) believes that entertainment is the psychological response of the audience to the media that has provided happiness for them. These psychological reactions are emotional reactions which will happen when the audience find attractive or useful information. $\mathrm{He}$ has explained why entertainment media particularly appeal to the audience. Moyer-Gusé (2008) believes that entertainment education is a popular communication strategy. It has been "injected into the mass entertainment content which contains pro-social behavior information, with the purpose of influencing the audience's cognition, attitude, and behavior, and spreads the health or education information included in the entertainment content of the mass media". Various media such as radio dramas, magazine articles, video games, comic books, movies, and television shows can be used to convey the message of entertainment education. Entertainment education is usually presented in narrative form, and most entertainment education focuses on health education, although entertainment education can also be used for other prosocial behaviors, such as various types of literacy education.

The mechanism of entertainment education has two points. First, entertainment education transmits information through narrative. Moyer-Gusé and Nabi (2010) explain that narrative refers to a story with "identifiable beginning, process, and end"; Green and Brock (2000) believe that narrative provides information about scenes, roles, and conflicts; puts forward unanswered problems or unresolved conflicts; and provides resolutions. Narrative is a story about a character. It is the joy and sorrow that a character encounters when he pursues his goal or unfolds an event.
Second, the transport effect helps entertainment education achieve its goal.

When people watch some television dramas, if they devote themselves to the TV series, they are completely attracted by the narrative and immersed in the story, as if they are "transported" from the real world to another world. When they are transported to a virtual world, they have been influenced by narratives and it is not easy for them to refute the story. The transport theory of Green and Brock (2000) argues that the focus of transportation is not the process of reading, but persuasion. The basic elements of transportation are: First, a story which can provide an opportunity for the audience; Second, the audiences leave their world and enter the world of the story; Third, changes of the audience after they have experienced the world of the story. Their research finds that, to some extent, individuals' are being brought into a story may have an impact on their faith in the real world. The two scholars accordingly conceptualize "transportation" as a unique psychological process that integrates attention, imagery, and emotions. When viewers are watching a story-based entertainment program, they may feel that they have been involved in a narrative world. At this time, "being transported into the narrative world" refers to the process in which individuals are immersed in stories. When individuals are experiencing stories, they don't have their trails in the real world (Gerrig, 1993; Green \& Brock, 2000). At this point, the audience has no incentive to interrupt this process and refute the story, so it can reduce resistance and increase persuasiveness.

\section{THE ELM MOdEL PRODUCED UNDER THE LEADERSHIP OF PERSUASION THEORY}

Persuasion is ubiquitous in politics, religion, psychology, education, and daily life, playing an active and important role. People try to influence others and are influenced by others. Scholars in the fields of psychology, communication, politics, marketing, and advertising have been tirelessly studying persuasion for many years.

Any process that may change someone's mind can be called persuasion. Persuasion can change a person's specific beliefs (eg, exercise is good for people's health), and it can also change a person's attitude. Attitude refers to people's general evaluation of other people, places, objects and problems. Attitude is the main object of influence, which affects people's choice and behavior (Petty \& Briñol, 2008). Since Aristotle's Rhetoric came out, researchers have been working on various factors that influence the effectiveness of persuasion.

Petty and Cacioppo elaborated an ELM model about attitude change from a social psychology perspective. The model believes that persuasion depends on the degree of people's fine processing on information. The audience's motivation (including degree of problem involvement, relevance of information, commitment of results, awakening of inconsistent information, cognitive needs, etc.) and ability (including being distracted or not, information comprehension, familiarity with the problem, proper knowledge structure, awakening effect of fear, etc.) are the main variables affecting 
the degree of audience's fine processing on information. Elaboration describes the degree of careful consideration of the received messages, and Likelihood refers to two approaches to the message, namely the central route and the peripheral route. The central route means that individuals with high motivation and high thinking ability think carefully about message arguments and then make judgment. The use of the central path for processing is more persistent and predictable. Peripheral path means that individuals, who have no motivation or ability, can't or do not want to think about message arguments, and only rely on peripheral information to judge. The use of the peripheral path for processing is transient and not predictable (Petty \& Cacioppo, 1986). Petty and Cacioppo $(1981,1986)$ thought that the central path of persuasion was particularly effective when there was a high probability of fine-tuning the disseminated message, and the peripheral path was effective when this probability was low.

In short, Petty and Cacioppo's model of fine processing possibilities describes two ways in which people are persuaded. One is the central path of persuasion, which is a very rational or very cognitive approach. People will read the information carefully and come up with many arguments against it. To persuade people, we must refute these arguments. Persuasion by the central route is difficult to succeed, especially when people find that the information they hear is contrary to their own ideas. The second is the edge path of persuasive, that is, included in the context of entertainment, various kinds of information can pass through people's strong defense systems and exert influence on people. Information that is not carefully read and thought produces convincing effects. Some of the hints in the information led people to accept information advice without cognitive thinking through unobtrusive methods. People are persuaded to watch movies and televisions designed for entertainment. The influence of the marginal path occurs during this period. ELM is used to explain the process of persuasion, that is, to explain how persuasive information ultimately achieves the purpose of persuasion through influencing attitudes; point out the differences of the audience's multiple responses to information and processing methods. The quantity and nature of the processing of relevant information triggered by persuasive information are the determinants of attitude formation or change.

\section{THEORETICAL ANALYSIS OF E-ELM MODEL}

These findings about ELM are obviously limited for understanding entertainment education. The researchers point out that the results of these ELM studies will only work when the topic is very persuasive and may directly affect the recipient's own interests. Moreover, the model does not consider that entertainment programs are different from general persuasive messages such as news and advertisements in the aspects of the motivation and goals (Slater, 1997; Slater \& Rouner, 1996). Slater and Rouner (2002) revised and used the ELM model on the basis of entertainment education theory, and put forward the refined processing possibility model of entertainment education on narrative processing.
The interpretation of this model can be carried out from two aspects: the absorption factor and persuasive mechanism of the E-ELM model.

\section{A. The Absorption Factors of the E-ELM Model Include the Following Four: Storyline, Production Quality, Intention, and Convergence}

The reason why people are passionate about stories is not single. In fact, narrative is very common in human experience and history. Social science discourse can only be partial and highlight the selected dimensions. Some researchers such as Rubin, Perse, and Powell (1985) emphasized the use of TV dramas to provide alternative social relationships; others such as Zillmann researched the excitement, dispersion, or transfer of the audience's attention brought by media entertainment; there are also some scholars such as Slater and Rouner (2002) who focus on how to deal with variables of persuasive content in narratives.

First, entertainment education has unique requirements for the quality of narratives. Entertainment education can attract viewers not because it has educational or persuasive content, but because it is dramatic (Singhal \& Rogers, 1999). If the content and purpose of persuasion are so obvious that they are more prominent than the narrative itself, the narrative may fail and persuasion will fail. Slater and Rouner (2002) believe that storyline appeal and high quality narratives can weaken persuasive intentions.

Second, it is also important to embed unobtrusive persuasive subtexts into narratives. In the entertainment narrative, the audiences mainly focus on characters, scenarios and events. The persuasiveness of narrative makes it possible for the audience to focus on the development and experience of the characters, which may make them at least temporarily accept the values and beliefs transmitted by the entertainment media. These values and beliefs may be inconsistent with their own beliefs.

Again, homophily has a positive effect. That is, audience perception similarity, sometimes called homogeneity. The audience perceives similarities with the roles in the play in physical characteristics, demographic characteristics, beliefs, personalities, or values. The recognition of characters by audiences, the similarities between audiences and characters, and even the relationship between audiences and characters, all rely on the absorption of narratives.

E-ELM predicts that a greater degree of problem involvement will lead the audience to pay more attention to the contentions related to the message. It will further determine the quality of the discussion and the changing attitude of the audience. Slater's (1997) research on narrative processing shows that when the information is a narrative, its persuasive intentions are less obvious. In other words, recognition of roles and participation in narratives are consistent with persuasive intentions (Green \& Brock, 2000; Slater, 1997).

The traditional study of the persuasive process admitted that the audience may refute the information, arguing that the generation of ideas that contradict or are inconsistent with the persuasive argument is the main obstacle to persuasion (Petty 
\& Cacioppo, 1986). Slater (1997) argues that narrative and counterargument are essentially incompatible in absorbing. If the recipient of the message is aware of and is generating a counterargument or counterexample in response to the persuasive intent of the message, the message will not be absorbed or transmitted and the roles cannot be identified. At this point, the recipient of the information has already separated from the narrative. If the recipient of the message is transported by the narrative, even if the persuasion intent is inconsistent with his previous attitudes, beliefs, or values, it will not be refuted when the information is experienced. Its connotation is that entertainment education influences individuals who usually resist persuasion by preventing their rebuttals.

\section{B. The Persuasion Mechanism of E-ELM}

The core concept of E-ELM is that when audiences watch entertainment television programs, their main purpose is to entertain themselves. As long as viewers are attracted to the program content and are transported into story situations, they will experience the emotion or personality of the story characters, be inclined to accept the beliefs or attitudes transmitted by the program, and not produce counter arguments. There are three mechanisms that produce persuasive effects: response to persuasive content, identification of roles, and consolidation.

After being organized a series of arrangements such as paving, dubbing, and editing, the TV drama works are presented to the audience and transformed into stories through the psychological effects of the audience. The psychological effects here are the empathy and involvement. The so-called involvement is that the audience is being attracted by the media content. According to the E-ELM model, the extent to which audiences are attracted when receiving media content determines their degree of involvement, and the degree of involvement is one of the mechanisms that produce persuasive effects (Slater \& Rouner, 2002). Because the audience is "involved" in the narrative, they have no motive for counterarguments (Green \& Brock, 2000). By "transporting" the audience to a narrative, it is possible to reduce the possible disputes, increase the audience's acceptance of the information contained in the narrative, improve the emotional identity and response, and produce persuasive effects. Green and Brock (2000) found that the content of the film will lead to a strong emotional response of the audience through transportation. Narrative is positively related to the effect of transportation, and the narrative structure is to produce convincing effects through the effects of transportation.

Another mechanism that produces persuasive effects is role recognition. Slater and Rouner (2002) discuss the definition of identity from two perspectives. The first is to emphasize that identity is an inherent emotional tendency. Identity is to turn others' traits into a part of the audience's own traits, and to attach importance to personal psychological structure. The second perspective is that identity is an external behavioral tendency. Individuals tend to behave in a similar manner to those who are their idols, and the intention of learning idols is valued. From this, it can be found that identity may be an internal psychological gain, or it may be an external behavioral manifestation, or both. Bandura (1971) also believes that if an individual accepts the thoughts, feelings and behaviors of others, it is called identity. Identity is a form of individual learning. Identity has started from infancy and results from the coordination of the id, the self, and the superego. In entertainment education, the audience internalizes the value or behavior of the identified role as their own personality traits, making their external behavior or mental state similar to the identification object. In other words, in the E-ELM model, the audience consciously or unconsciously shapes the self through identifying roles, and integrates the character's personality, emotions, and behaviors into their own psychological structure, forming the tendency of learning from idols.

The third mechanism to produce persuasive effects is to strengthen consolidation. Slater and Rouner (2002), in addition to retrospectively analyzing individual's cognitive reactions, have found that discussing with others as a response in social public places is an extension of social relations induced by drama. The success of entertainment education includes audience's discussion of roles, they talk about them as if they are real people (Singhal \& Rogers, 1999). The recording and analysis of these discussions may provide ways to measure a series of processes related to the counterarguments, identifications, and empathy of the roles. 


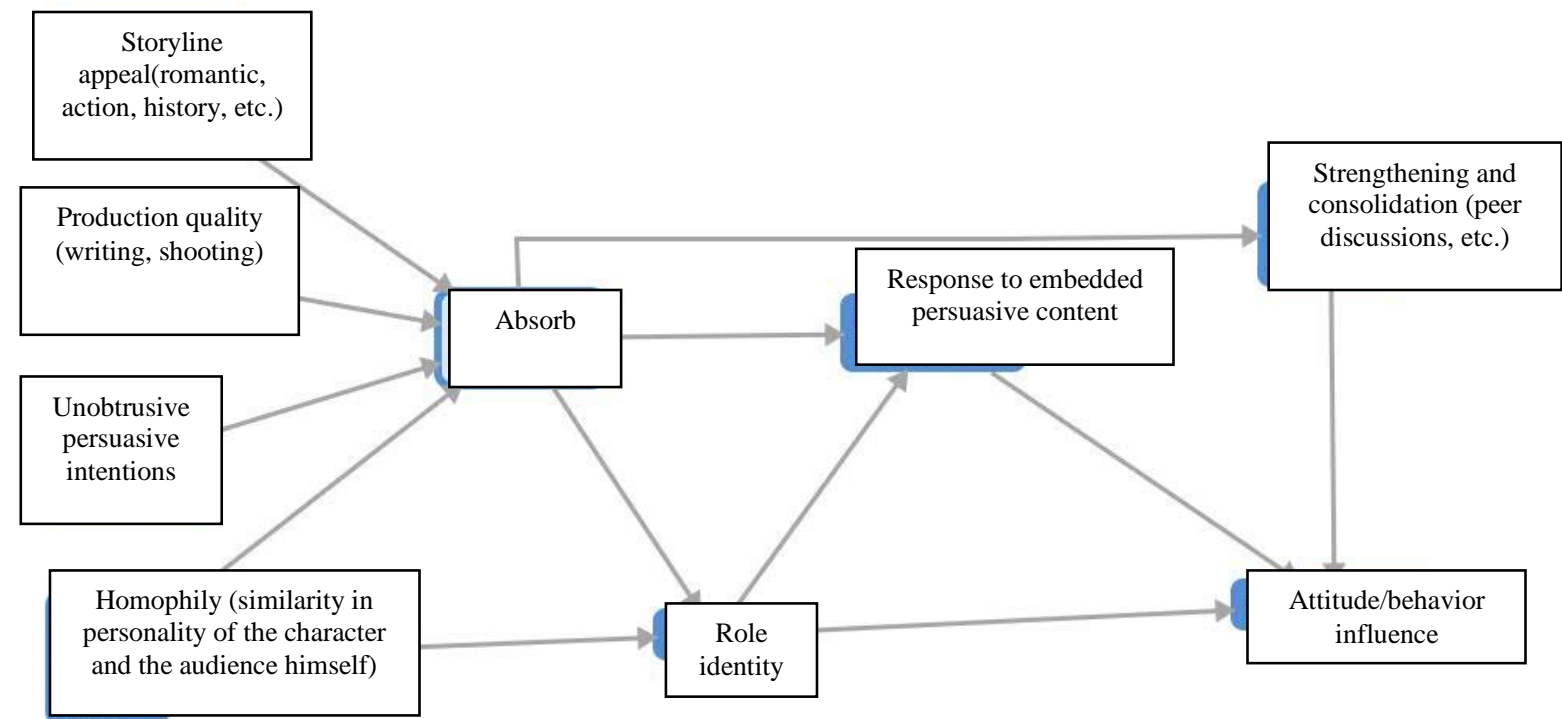

Fig. 2. Extended-elaboration likelihood model.

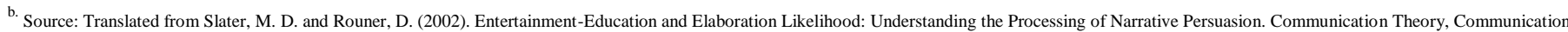
Theory, 12, 173-191. doi:10.1111/j.1468-2885.2002.tb00265.x

\section{CONCLUSION}

In summary, the social cognitive theory and the triadic interaction determinism constitute the theoretical foundation for the concept of entertainment education. The action mechanism of entertainment education is the interaction between narrative theory and transport theory. The ELM model led by the persuasive theory is also the foundation of the formation of E-ELM mode. The final E-ELM model promotes the understanding of entertainment education theory.

\section{REFERENCES}

[1] Bandura, A. (1971). Social learning theory. New York: General Learning Press.

[2] Bandura, A. (1986). Social foundations of thought and action: A social cognitive theory. Englewood Cliffs, NJ: Prentice-Hall, Inc.

[3] Bandura, A. (2002). Social cognitive theory of mass communication. In J. Bryant, \& D. Zillmann (Eds.), Media effects: Advances in theory and research (pp. 121-154). Mahwah, NJ: Lawrence Erlbaum.

[4] Bandura, A. (2004). Social cognitive theory for personal and social change by enabling media. In A. Singhal, M. J. Cody, E. M. Rogers, \& M. Sabido (Eds.), Entertainment-education and social change: History, research, and practice (pp. 75-96). Mahwah, NJ: Lawrence Erlbaum.

[5] Gerrig, R. J. (1993). Experiencing narrative worlds. New Haven, CT: Yale University Press

[6] Green, M. C., \& Brock, T. C. (2000). The role of transportation in the persuasiveness of public narratives. Journal of Personality and Social Psychology, 79, $701-721$.

[7] Green, M. D., \& Brock, T. C. (2002). In the mind's eye: Transportation-imagery model of narrative persuasion. In M. C. Green, J. J. Strange, \& T. C. Brock (Eds.), Narrative impact: Social and cognitive foundations (pp. 315 - 341). Mahwah, NJ: Erlbaum.

[8] Morgan, S. E., Movius, L. and Cody, M. J. (2009), The Power of Narratives: The Effect of Entertainment Television Organ Donation Storylines on the Attitudes, Knowledge, and Behaviors of Donors and Nondonors. Journal of Communication, 59, 135-151. doi:10.1111/j.1460-2466.2008.01408.x
[9] Moyer-Gusé, E. (2008). Toward a theory of entertainment persuasion: Explaining the persuasive effects of entertainment-education messages. Communication Theory, 18(3), 407-425.

[10] Moyer-Gusé, E. and Nabi, R. L. (2010), Explaining the Effects of Narrative in an Entertainment Television Program: Overcoming Resistance to Persuasion. Human Communication Research, 36, 26-52. doi:10.1111/j.1468-2958.2009.01367.x

[11] Petty R. E., Briñol P. (2008) Persuasion: From Single to Multiple to Metacognitive Processes Perspectives on Psychological Science 3(2), 137-147 doi: 10.1111/j.1745-6916.2008.00071.x

[12] E., Cacioppo, J. T., \& Goldman, R. (1981). Personal involvement as a determinant of argument-based persuasion. Journal of Personality and Social Psychology, 41(5), 847-855 doi: http://dx.doi.org/10.1037/00223514.41.5.847

[13] Petty, R.E., \& Cacioppo, J.T. (1986). Communication and persuasion: Central and peripheral routes to attitude change. New York: SpringerVerlag.

[14] Rubin, A. M., Perse, E. M., \& Powell, R. A. (1985). Loneliness, parasocial interaction, and local television news viewing. Human Communication Research, 12, 155-180 DOI: $10.1111 / \mathrm{j} .1468$ 2958.1985.tb00071.x

[15] Singhal, A. and Rogers, E. M. (2002). A Theoretical Agenda for Entertainment-Education. Communication Theory, 12, 117-135. Doi:10.1111/j.1468-2885.2002.tb00262.x

[16] Singhal, A., \& Rogers, E. (1999). Entertainment-education: A communication strategy for social change (pp. 9). Mahwah, NJ: Lawrence Erlbaum

[17] Slater, M. D., \& Rouner, D. (1996). Value affirmative and value protective processing of alcohol education messages that include statistics or anecdotes. Communication Research, 23, 210-235. https://doi.org/10.1177/009365096023002003

[18] Slater, M. D. (1997). Persuasion processes across receiver goals and message genres. Communication Theory, 7, 125-148. DOI: 10.1111/j.1468-2885.1997.tb00145.x

[19] Slater, M. D. and Rouner, D. (2002). Entertainment-Education and Elaboration Likelihood: Understanding the Processing of Narrative Persuasion. Communication Theory, 12, 173-191. doi:10.1111/j.14682885.2002.tb00265.x

[20] Slater, M. D.(2002). Entertainment education and the persuasive impact of narratives. In M. C.. Green, J. J. Strange, \& T. C. Brock (Eds.) 
Narrative impact: Social and cognitive foundations (pp. 157-181). Mahwah, NJ: Lawrence Erlbaum.

[21] Zillmann, D. (2000). Basal morality in drama appreciation. In I.

Bondebjerg (Ed.), Moving images, culture, and the mind (pp. 53-63).

Luton, UK: University of Luton Press. 